\section{Priority conservation areas of the Coral Triangle}

With an enormous, largely unprotected ocean, it's useful to identify areas of the most conservation importance. The authors looked at the Coral Triangle to determine which areas therein should be prioritized for conservation.

Based on previous research by the authors, a set of eight criteria were used to identify these areas. Four criteria were based on habitats: uniqueness, fragility, importance for ecological integrity, and areas that were representative of many habitats. The other four criteria were focused on species: the presence of threatened species, species with limited ranges, areas with high species richness, and areas that are unique for the development of certain species.

The distributions of coral reefs, seagrass meadows, and mangrove forests were considered sensitive habitats. Species on the IUCN Red List marked as Critically Endangered (CR), Endangered (EN) or Vulnerable (VU) were selected as species of special conservation concern, as well as those on CITES Appendices 1 and 2. Ranged-limited species were defined as "reef fish species with a spatial distribution of less than 5 million $\mathrm{km}^{2}$ and whose known range is only within the Coral Triangle."

To find areas of biodiversity importance, each layer of information was spatially superimposed on top of the other. Geographic data like this is typically analyzed in "cells" determined by latitude and longitude. In this case, each "cell" was about $55 \mathrm{~km}^{2}$. "Clustered hotspots" are areas where a group of cells were significant to biodiversity, and given their size, were considered important for regional conservation efforts. Individual cells of biodiversity importance were also identified for more site-based conservation efforts. Hotspots and coldspots of biodiversity were mapped at the $99 \%, 95 \%$, and $90 \%$ confidence levels by statistically comparing the biodiversity scores of the superimposed data for a given cell to that of its neighbors.

Almost $13 \%$ of the coral triangle was considered a biodiversity hotspot under this analysis. The hottest hotspots were in "the ecoregion of eastern Philippines, Palawan/North Borneo, Makassar Strait, Halmahera, the Bird's Head region of Indonesian Papua, Lesser Sunda Islands, Banda Sea, north-eastern part of the Papua New Guinea and the Solomon Sea." Site-based analysis identified local hotspots as the Verde Island Passage, the southern part of Negros Island, and Cebu Island of the Philippines, and the northern tip of Sulawesi, Ambon Island, Kei Islands, and the Raja Ampat Archipelago of Indonesia.

834 species of conservation concern were identified in this analysis, but these species are represented in less than $1 \%$ of the area identified as hotspots. With an area as diverse and globally ecologically important as the Coral Triangle, even protecting biodiversity hotspots leaves many species unprotected.

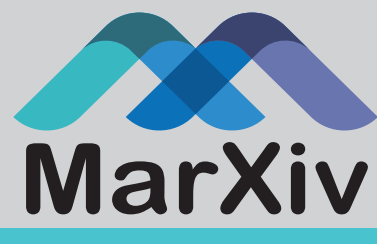

This is a summary of: Delineating priority areas for marine biodiversity conservation in the Coral Triangle

Accessible at: https://marxiv.org/4y69v

Authors: Irawan Asaad, Carolyn J. Lundquist, Mark V. Erdmann, Mark J. Costello

Added to MarXiv: May 2018

Published: Biological Conservation, 2018

Suggested Citation: Priority conservation areas of the Coral Triangle. OCTO (2018). DOI: 10.17605/OSF. IO/82BG3

See more MarXiv summaries at https://www.marxivinfo.org/ summaries

Join the MarXiv Summaries monthly newsletter at https:// oct.to/marxivsum

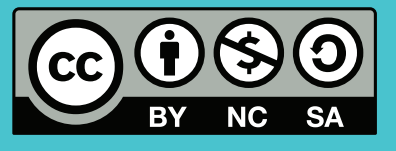

MarXiv is an ОCTO Initiative

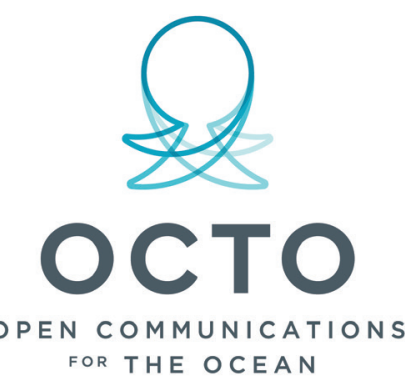

